\title{
El Colegio del Estado de Puebla y el Primer Congreso Nacional de Estudiantes en 1910
}

The Puebla College State and the First National Student Congress, 1910

Maria de Lourdes Herrera Feria

Benemérita Universidad Autónoma de Puebla mlhferia@gmail.com

\section{Resumen}

En las líneas siguientes se revisa la participación de los estudiantes del Colegio del Estado de Puebla, sus reflexiones y sus propuestas en el Primer Congreso Nacional de Estudiantes que se celebró en 1910 como parte de los festejos del centenario del movimiento de independencia. El objetivo de esta contribución es reseñar sus críticas a la práctica educativa en la enseñanza secundaria y superior, así como a la política educativa del régimen porfirista.

Con este fin primero se hace un recuento de la historia del Colegio del Estado en la primera década del siglo xxy, enseguida, se examinan las ponencias que se presentaron durante el Primer Congreso Nacional de Estudiantes. Esta exposición se basa en la información localizada en el Fondo de Instrucción Pública y Bellas Artes del Archivo General de la Nación y en las aportaciones de la bibliografía especializada en el tema.

Palabras clave: Colegio del Estado de Puebla, Primer Congreso Nacional de Estudiantes, Estudiantes, Organización estudiantil

\section{Abstract}

This article revises the participation of the Puebla State College students in the First National Student Congress of 1910, a congress that took place as part of the centenary festivities of the Independence movement. The aim is to analyze the students' criticisms to the teaching practices of middle and high schools as well as to the educational policies of the Porfirio Díaz' regime.

The article begins with an overview of the history of the Puebla State College in the first decade of the twentieth century, followed by the analysis of the papers presented at the First National Student 
Congress. My research is based on documents from the Fund Instrucción Pública y Bellas Artes of the Archivo General de la Nación and on specialized bibliography.

Keywords: Puebla College State; First National Congress of Students; students; student organization

\section{Presentación}

La máxima casa de estudios del estado de Puebla en el siglo XIX era conocida como Colegio del Estado y se erigió sobre el legado de los colegios fundados por los jesuitas en el periodo colonial. Después de su expulsión de los territorios de la monarquía hispánica, decretada por Carlos III en 1767, los colegios de la orden ignaciana quedaron bajo la jurisdicción del clero secular y en 1790, bajo el gobierno diocesano del IImo. Salvador Biempica y Sotomayor, se dispuso que los colegios de San Ignacio, de San Gerónimo y del Espíritu Santo se fusionaran para dar paso a una nueva institución: el Real Colegio Carolino con sede en el edificio del Antiguo Colegio del Espíritu Santo.

A partir de $1825^{1}$ el plantel quedó bajo la tutela del gobierno civil de manera absoluta. Se le nombró Colegio del Estado y para que se hiciera patente su dependencia del gobierno estatal al gobernador se le atribuyó la prerrogativa de nombrar al rector, además de aprobar la designación de funcionarios y catedráticos, asignar becas a los estudiantes, sancionar los cambios en las cátedras y en la administración interna del colegio, y autorizar los fondos para su funcionamiento.

Esta injerencia del gobierno civil en la vida interna del colegio correspondía a una tendencia general en la naciente república federal mexicana. El marco jurídico y político establecido en la Constitución de 1824, que declaró a los estados independientes, libres y soberanos dejó la iniciativa a los gobiernos estatales para fomentar la instrucción en todos los niveles, con rentas públicas, dentro de sus propias demarcaciones; en cada entidad o región de México los gobiernos locales procuraron refundar o crear establecimientos para realizar estudios medios y superiores que, posteriormente, se convertirían en el antecedente de varias de las universidades estatales del siglo xx (Ríos, 1998: 193-194).

1 "Oficio del gobernador constitucional del estado de Puebla, José Ma. Calderón, al rector del Colegio, Ignacio Conzález de la Peñuela, del 11 de junio de 1825, con el que se hace entrega de dos ejemplares del decreto del H. Congreso que otorga al gobierno estatal la suprema inspección de ese Colegio, para su inteligencia y fines consiguientes". Véase Benemérita Universidad Autónoma de Puebla., Biblioteca Histórica José María Lafragua (BHJML), fondo Colegio del Estado. Secretaría del Colegio del Estado. Oficios, 1820-1831. 
Así, la existencia de estas instituciones en general y del Colegio del Estado de Puebla en particular quedó vinculada a la inestabilidad política y a las graves carencias económicas, propias de un Estado en proceso de formación.

La consolidación institucional del Colegio del Estado vendría después de la restauración de la república; en el último tercio del siglo XIX se impuso una orientación positivista en sus planes de estudio, se reformaron y adecuaron sus instalaciones y se reelaboró su reglamento interno mismo que perduraría hasta 1937 cuando el Colegio del Estado se convertiría en la Universidad de Puebla.

La primera década del siglo xx mexicano registró los efectos del saneamiento de la hacienda pública y del impulso a las actividades productivas, entre las que se privilegiaron las llamadas industrias nuevas. La obtención de superávit por primera vez en la historia de México permitió orientar el gasto público hacia la extensión de la red ferroviaria, la modernización y ampliación de los puertos marítimos, al pago de la deuda pública y también a mejorar la oferta de bienes y servicios como justicia, salud y educación (Carmagnani, 2003: 227).

La aplicación de recursos a las tareas educativas y el consenso para que la educación se extendiera a todos los sectores sociales favorecieron la organización y la institucionalización del sistema educativo mexicano. Pero la educación no sólo sirvió para mejorar las condiciones de vida de la población, sino que también alentó su aspiración a una mayor participación en los asuntos públicos y en la toma de decisiones.

El aula, además de ser un espacio educativo, devino en un nuevo y dinámico espacio de socialización donde se constituyeron solidaridades de corte moderno; allí, vinculados por afanes formativos e inclinaciones profesionales homogéneas, se asociaron individuos de diverso origen para actuar de manera colectiva (Guerra, 2003 [1]: 126-127). Y en particular el ámbito de la educación superior favoreció la integración de grupos capaces de elaborar interpretaciones de su entorno social y de diseñar estrategias para transformarlo. Es en este contexto que nos interesa primero presentar el devenir del Colegio del Estado de Puebla durante la primera década del siglo xx para abordar la participación de sus estudiantes en los eventos que precedieron al estallido del movimiento revolucionario y, enseguida, examinar su intervención en el Primer Congreso Nacional de Estudiantes organizado como parte de los festejos del primer centenario del movimiento de independencia. Para acometer esta tarea aquí se retoma la información recabada en el Fondo de Instrucción Pública y Bellas Artes del Archivo General de la Nación, así como las aportaciones de la bibliografía especializada en el tema. 


\section{El Colegio del Estado de Puebla en los albores del siglo XX}

Al iniciar el siglo xx el estado de Puebla era gobernado por el general Mucio P. Martínez quien asumió el cargo en 1892 y, con el favor de Porfirio Díaz, el gran elector, se mantendría en el cargo hasta los primeros meses de 1911. Puebla contaba con poco más de 1021000 habitantes en los 22 distritos en los que estaba dividida la entidad, en cuatro de los cuales se concentraba la tercera parte de la población del estado, a saber, Puebla, Tehuacán, Chalchicomula y Huauchinango, y cada uno tenía una población de alrededor de 70000 habitantes (Lomelí, 2001: 282).

Después de dos siglos, la ciudad de Puebla, parecía recuperar el dinamismo demográfico que, antaño, la había distinguido; las casas y edificios que servían de morada en el antiguo casco urbano resultaron insuficientes y la ciudad se extendió hacia el poniente, los terrenos ubicados entre la penitenciaría de San Javier y el cerro de San Juan empezaron a ser motivo de especulación y ocupación para dar cabida a una población de casi noventa y nueve mil personas que residían en el municipio donde estaba ubicada la capital del estado. Entre ellos se contaban 366 profesores, 169 abogados, 75 médicos, 128 sacerdotes del culto católico y 4 oficiantes de otros cultos que atendían las necesidades espirituales de 98,520 católicos y de 403 protestantes (SE, 1956). Y, en materia educativa, la autoridad estatal hizo notar que se habían pagado con exactitud y puntualidad los sueldos de profesores y ayudantes que servían en las escuelas primarias dependientes del Ejecutivo, que se habían proporcionado útiles e instrumentos de trabajo y que se había inaugurado la primera escuela primaria superior conforme a la ley vigente sobre instrucción pública (CEP, 1901: 274).

En el ámbito de la educación superior, los últimos años del siglo xIx y la primera década del siglo xx significaron un período de fructífera renovación de los estudios y cátedras y de aliento a las observaciones científicas, pero también de adaptación a los requerimientos de las nuevas actividades productivas: las enseñanzas prácticas que capacitaban para el trabajo en el corto plazo ganaron terreno, los cursos de telegrafía práctica y los que preparaban para las actividades comerciales ganaron el favor del público y tuvieron mayor demanda, mientras las largas carreras profesionales, como la medicina y la abogacía, vieron mermar su matrícula. Profesionales del magisterio y artesanos calificados empezaron a egresar regularmente de las escuelas normales y de las escuelas de artes y oficios. Y como hecho notable se registró la incorporación de las mujeres a las aulas del Colegio del Estado entre 1901 y 1902.

En este establecimiento, la clase de telegrafía práctica fue creada después de escuchar el parecer de la presidencia de la república, expresado mediante el mandato del gobernador del estado, para que a ella asistieran todas las personas que así lo desearan, sin exigirles requisito alguno. Al abrirse al público se procuró dotar a la cátedra de todos los aparatos 
necesarios. En ese tenor, también por iniciativa del gobierno del estado, se fundaron las clases de economía política y de derecho mercantil y de minas para la carrera de Comercio con el carácter de gratuitas. La creación de esas clases tuvo el propósito de mejorar los estudios mercantiles y, así, favorecer especialmente los estudios que podían contribuir al acertado ejercicio de las nuevas actividades económicas.

Presidido por el licenciado José Rafael Isunza, de 1894 a 1910, el Colegio del Estado fue estimado como el centro estatal, por excelencia, de la educación pública superior, su edificio fue empeñosamente mejorado a principios del siglo XX, especialmente para recibir a los delegados de la Segunda Conferencia Pan-Americana quienes, invitados por el gobernador, fueron recibidos ceremoniosamente en su salón de actos. Las autoridades del Colegio aprovecharon esa oportunidad para mejorar el gabinete de física y el observatorio meteorológico.

Sus cátedras de telegrafía y de anatomía continuaron beneficiándose con la adquisición de útiles e instrumentos, el profesor de esta última se encargó de solicitar a Europa, o de que se construyeran en Puebla, algunos aparatos y objetos que eran indispensables para la práctica de disecciones. También se obtuvo la autorización para que los cadáveres, en los que los alumnos estudiaban prácticamente la anatomía, permanecieran el tiempo necesario, debidamente conservados, en el Hospital General.

En esa época el gobernador dispuso, y la academia del Colegio atendió solícitamente la orden, establecer un plan de enseñanza para los jóvenes, que tuvieran edad y aptitudes, interesados en formarse como oficiales reservistas. Los alumnos harían ese aprendizaje en el tercer, cuarto, quinto y sexto año de instrucción secundaria. En el primer año, su formación comprendía el estudio de la geografía física, la geografía patria y tomarían el primer curso de ejercicios militares de infantería, sin armas; en el segundo año, se ejercitarían en la caballería, sin armas; en el tercer año ya se les instruiría en el manejo de las armas, para ello aprenderían la descripción y uso del fusil, se aplicarían a la práctica de la esgrima con la bayoneta en combate individual, ensayarían tiro al blanco con fusil y pistola, aprenderían la descripción del sable y practicarían su manejo a pie y a caballo, también se ejercitarían en el uso de la carabina a pie y a caballo, además repasarían los ejercicios militares de infantería y caballería, aprendidos en años anteriores, pero ahora con armas; en el cuarto año, repetirían los ejercicios del curso anterior, estudiarían la parte relativa a fortificación pasajera del campo de batalla y rudimentos de topografía militar en los manuales publicados por la Secretaría de Guerra.

El Colegio del Estado, la Escuela de Artes y Oficios y las Escuelas Normales, asentadas en la ciudad capital, recibieron el apoyo económico de un régimen que, habiendo logrado estabilizar el gasto público, estaba en condiciones de invertir en infraestructura educativa. Bajo la supervisión y protección del gobierno del estado, encabezado por el general Mucio P. Martínez, los edificios que albergaban estas instituciones fueron renovados y hermoseados, las escuelas normales poblanas incluso fueron relocalizadas en un nuevo edificio, especialmente 
diseñado para su objeto; nuevas cátedras se introdujeron y se dotaron con útiles y aparatos más modernos.

En la última década del régimen porfirista, nada sucedía en el ámbito educativo poblano sin la supervisión y aprobación del gobierno del estado. Esta situación era particularmente visible en el Colegio del Estado: desde el nombramiento y la supervisión del personal docente y administrativo, o el ingreso de los colegiales, hasta la organización de los estudios, o el financiamiento de la institución, toda su vida escolar era controlada por el poder estatal que no solamente se ocupaba del auxilio material a la educación sino, principalmente, de la planeación y organización de la enseñanza.

En 1901, el Colegio del Estado contaba con 273 alumnos: 124 matriculados y 149 no matriculados, quienes necesariamente eran externos y sin beca. De los 124 alumnos que si estaban matriculados, 95 eran externos y 29 internos; de estos, sólo 17 tenían una beca de gracia. De los 273 alumnos que formaban la población escolar del Colegio del Estado, 179 cursaban la instrucción secundaria, 76 las cátedras de comercio y 18 las cátedras de medicina (GEP, 1903: 308-315).

La enseñanza de las lenguas modernas, que en el Colegio del Estado se había iniciado desde los tiempos de la restauración de la república, obtuvo una renovada atención frente a las posibilidades que parecía ofrecer la diversificación de la relaciones comerciales del régimen. La preeminencia que había alcanzado la enseñanza del francés, porque los textos usados en los colegios eran franceses, se fue perdiendo frente a la comprobación de que la ciencia, la literatura, y en general, la cultura de otros países era tan útil y pertinente como las de la culta Francia. Entonces, era igualmente necesario aprender inglés, alemán, italiano y algún otro idioma para conocer a fondo las producciones culturales de las diversas naciones civilizadas y, ante la imposibilidad de enseñar todos los idiomas, se optó por dar preferencia a aquellos de los que se podía obtener mayor ventajas, tanto en la vida práctica como en el perfeccionamiento de los estudios profesionales.

El acercamiento a la economía y a la cultura de los Estados Unidos de Norteamérica impuso la enseñanza del idioma inglés. Comercio, ciencia, industria, arte en inglés fluían con regularidad a nuestro país; un considerable número de americanos se establecía en suelo poblano, lo mismo que sus capitales y sus negocios. Ante ese panorama, en sus informes, el gobernador declaraba su interés por alentar, entre la población, la enseñanza de la lengua más usada en el mundo en ese momento y, con ese objetivo en mente, no dudaba en aprobar los gastos que implicaban su enseñanza, más elevados que los de la enseñanza de otras lenguas; la necesidad y la utilidad de la enseñanza del inglés fueron los argumentos que esgrimió el gobierno estatal para reformar los artículos 62, 102, y 114 de la Ley Orgánica de Instrucción Pública, reformas aceptadas por el Congreso el 9 de enero de 1903 y sancionadas 
tres días después y, así, se dio preferencia a la enseñanza del idioma inglés, sobre otras lenguas, en los programas instrucción secundaria y de estudios superiores (GEP, 1905: 349-351).

Para 1905, la matrícula del Colegio del Estado creció. Se reportó la asistencia de 534 alumnos varones, 251 matriculados y 283 no matriculados, a éstos había que sumar 125 estudiantes mujeres, de las cuales 56 estaban matriculadas y 69 no estaban matriculadas. Durante ese año se abrieron todas las clases de instrucción secundaria, las de los tres primeros años de la carrera de comercio, las del primer y tercer curso de derecho, las de primer, segundo, tercer y quinto año de medicina y las del primer año de farmacia. Los 534 alumnos varones se distribuyeron de la manera siguiente: 257 en instrucción secundaria, 84 en la carrera de comercio, 131 en la cátedra de telegrafía, 27 en las cátedras de derecho, 33 en las cátedras de medicina y 2 los cursos de farmacia. Por su parte, las 125 estudiantes mujeres tomaron las clases siguientes: 29 las de instrucción secundaria, 14 las de la carrera de comercio, 77 las de telegrafía y 5 las de obstetricia. Sustentaron examen de partera las señoritas: Guadalupe Vázquez, Canuta Tlapale, María Pérez y María Camaño. Los alumnos Francisco Casián y Miguel Moreno terminaron sus estudios profesionales de medicina. Y de acuerdo al informe que se rindió ese año, todos los alumnos pensionados tuvieron un buen desempeño escolar, lo que les permitió conservar la beca que les otorgaba el gobierno.

Los informes que rindió el presidente del Colegio del Estado, el licenciado José Rafael Isunza, y que fueron incorporados textualmente como anexos a las memorias de gobierno, consignaron las medidas tomadas para consolidar la enseñanza superior y las prácticas científicas en sus aulas. Con detalle se reportó el incremento, mediante importaciones de Europa, del arsenal de útiles, instrumentos y sustancias; el ingreso de nuevos títulos al acervo de su biblioteca; la constancia con que se practicaron observaciones meteorológicas que fueron enviadas al Observatorio Central de México; el crecimiento de sus gabinetes con la adición de nuevos ejemplares así como, el constante mantenimiento y cuidado de sus instalaciones (GEP, 1907: 421-424).

La atención que se dispensó a la educación se orientó a propagar las ideas positivistas en los planes y programas de estudio de las escuelas públicas y, al mismo tiempo, se permitió el retorno, más o menos disimulado, de la religión a las aulas. Colegios y centros educativos confesionales se establecieron con la tolerancia del gobierno del general Mucio P. Martínez. A pesar de las voces y señalamientos de los liberales que alegaban la contravención a las leyes de Reforma en materia educativa, desde 1898 había empezado a funcionar la Escuela Normal Católica y, en 1903 con la autorización de Pío X, el Seminario Palafoxiano fue elevado a la categoría de plantel universitario, convirtiéndose en la Universidad Católica de Puebla.

Esta proliferación de escuelas católicas y el arribo de nuevas órdenes religiosas dedicadas a la educación y a la labor pastoral entre los jóvenes, en la primera década del siglo xx poblano, 
tuvieron como efecto nuevas inversiones en la educación pública para acallar las críticas de los liberales ante la tolerancia del gobierno estatal. En 1905 comenzó la construcción del Centro Escolar Modelo en la ciudad de Puebla, que fue inaugurado tres años después, sería la última gran obra educativa del gobierno porfirista poblano y una de las escuelas más prestigiadas del estado (Lomelí Vanegas, 2001: 287).

Tanto la tolerancia a la educación confesional, producto de iniciativas particulares, como la inversión gubernamental en la educación fortalecieron la rectoría del Estado en materia educativa, pues desde la esfera gubernamental emanaban la condescendencia para el funcionamiento de escuelas privadas y los recursos para consolidar las escuelas públicas y, a pesar del activismo de los particulares, difícilmente podían competir contra el presupuesto que el gobierno destinaba a la educación. De esta manera, en aquellos años se construyó la preeminencia de la educación pública como la mejor opción para la juventud estudiosa sobre la educación confesional.

En 1909 el presidente del Colegio del Estado informó que se continuaban impartiendo, conforme a los programas respectivos, las clases correspondientes a la Instrucción Secundaria, a la carrera especial de Comercio, a la enseñanza de telegrafía práctica y a las profesiones de Derecho, Medicina, Ingeniería y Obstetricia, y destacaba el aumento de alumnos matriculados en estas últimas. Con detalle menciona que, a iniciativa de la Sociedad Astronómica de México, el 12 de mayo de 1909 se celebró en el Colegio, mediante una fiesta científico-literaria, el tercer centenario de la invención del anteojo astronómico por Galileo y que en esa misma fecha se inauguró el Observatorio Astronómico y Meteorológico del plantel, mejora que importó 31187.75 pesos, y que para la correcta utilización del magnífico anteojo ecuatorial astrofotográfico, que formaba parte importante y esencial de dicho Observatorio, fue necesario reformar la planta de empleados, hacer una instalación de alumbrado eléctrico y reglamentar convenientemente el servicio, todo en aras de que el primer centro de instrucción de Puebla se encontrara, como siempre, al frente de los más adelantados en su género en la república. También informó que se seguían aumentando las dotaciones de aparatos y utensilios de los gabinetes de física y química en el sentido que lo reclamaban los adelantos científicos; se compraron pupitres nuevos para las clases, se cambió el sistema de cañerías que surtía de agua potable al colegio, se repararon completamente los aparatos del gimnasio para los ejercicios de los alumnos; y se acrecentó con 253 obras el fondo de la biblioteca José María Lafragua gracias al legado de su benefactor, el señor don Manuel Maneyro, y a compras hechas por el colegio con sus propios fondos además de donativos diversos (GEP, 1911: 314-316).

Pero, al mismo tiempo que la educación — desde la instrucción elemental hasta la capacitación para el trabajo o la formación profesional - se perfilaba como el mecanismo idóneo para el mejoramiento de las condiciones de vida de la población, también hacía posible una 
mayor intervención de los ciudadanos en los asuntos de la vida pública. La crítica y la oposición al orden corporativista y al sistema político que marginaba a las mayorías en la toma de decisiones encontraron en la población educada a sus mejores voceros.

Los primeros indicios documentados de la rebeldía estudiantil en Puebla se registran desde el último lustro del siglo XIX, a propósito de la guerra de independencia de Cuba la cual terminaría en 1898. Los estudiantes del Colegio del Estado, que no podían expresar su inconformidad por la falta de libertades políticas en México, no dudaron en manifestarse por la causa independentista cubana. La comunidad estudiantil, siempre idealista y entusiasta pugnaba por la libertad, aunque fuera la ajena, y en varias oportunidades se lanzó a la calle gritando consignas contra la España opresora, aun sabiendo que la comunidad española gozaba de gran influencia en las altas esferas del gobierno estatal y nacional. Años después, Francisco L. Casián, quien fuera director del Colegio del Estado entre 1917 y 1920, rememora el espíritu que a finales del siglo XIX animaba a los jóvenes estudiantes de la institución: "En todos los tiempos y en todos los lugares del planeta, la juventud es siempre igual, soñadora, entusiasta, batalladora y atrevida; siempre noble, siempre guerrera, nunca aguerrida; pero 'guerrista' siempre [...]. No tiene escudo porque le falta experiencia; pero no vacila en ofrecer su pecho para defender las causas que le son queridas [...]" (Casián, 1998: 112). Recuerda cómo los estudiantes salieron del colegio, arrebatadamente, gritando "vivas" a Cuba y "mueras" a España arengando a la multitud congregada en un club del edificio de la Aduana Vieja con una catilinaria furibunda contra la opresión de que era víctima la "perla de las Antillas" (Casián, 1998: 114). La juventud poblana educada, bajo la máxima "el progreso como fin, el orden como medio", ensayó su rebeldía pero en esa ocasión fue hábilmente domeñada por la férula disciplinaria de las autoridades escolares.

Sin embargo, el espíritu de rebeldía estudiantil resurgiría en 1909 cuando la agitación política en la ciudad de Puebla alcanzó niveles insospechados. A la movilización de los obreros textiles se sumaron el resentimiento ante las medidas represivas del régimen contra los trabajadores, el descontento por la concentración de la riqueza en pocas manos y la pauperización de amplias capas de la población, la angustia por los efectos de las crisis económicas de 1905 y de 1907 —agravadas por las sequías las cuales provocaron el desabasto de alimentos - y el rechazo a la falta de libertades políticas. Las críticas al régimen porfirista se fueron aglutinando en un movimiento de resistencia que disponía para su configuración de un grupo de letrados que no se limitaban a participar en manifestaciones públicas, sino que, haciendo uso de sus habilidades y competencias, expresaban y difundían sus ideas de manera organizada y sistemática a través de medios impresos, lo que daba una mayor proyección a sus propuestas.

En Puebla el movimiento abanderado por Francisco I. Madero animó la formación de varios grupos que se pueden clasificar en dos vertientes: una, heredera de las ideas magonistas del 
Partido Liberal Mexicano (PLM), tuvo como figura nuclear a Aquiles Serdán quien en 1909 fundó el club antireeleccionista Luz y Progreso y difundió sus críticas a los gobiernos estatal y federal en el periódico La no reelección, lo que le valió su detención de septiembre a diciembre de ese año (Lomelí, 2001: 294); la otra vertiente, de tendencia moderada, que expresaba una marcada aversión al programa radical del PLM y, por consiguiente, a la jefatura de Aquiles Serdán, salió a la palestra pública en mayo de 1910 cuando un grupo de simpatizantes del general Bernardo Reyes, aspirante a la presidencia, decidió apoyar a Madero y fundar el Club Central Antireeleccionista (Tecuanhuey, 1994: 11). Pero independientemente de filiaciones radicales o moderadas lo cierto es que la participación estudiantil dentro del proceso electoral en 1910 se decantó por la ruptura con el régimen y encontró en el apoyo a la candidatura maderista una vía de expresión como respuesta a la marginación política, social y económica que prevaleció durante el Porfiriato.

En ambas vertientes militaron alumnos del Colegio del Estado, de la Universidad Católica, de la Escuela Normal y del Instituto Metodista Mexicano (Fuentes, 1999), a los que no sólo asistía la juventud poblana, sino también la proveniente de los estados de Guerrero, Oaxaca, Tlaxcala, Hidalgo y Veracruz. Sin embargo, hay que mencionar que buena parte de los alumnos del Colegio del Estado se declararon maderistas, no así serdanistas.

Ambos clubes — Luz y Progreso y Central Antireeleccionista—, junto con otras 25000 personas, brindaron una entusiasta recepción a Madero el 14 de mayo de 1910, pero al día siguiente de su visita las autoridades poblanas se dieron a la tarea de desarticular el movimiento opositor, que crecía día a día. Sin hacer distinción entre radicales o moderados emprendió acciones represivas contra los integrantes de los dos clubes. Entre los más visibles se contaban los estudiantes y profesores del Colegio del Estado de Puebla. En primer término se prohibió, expresamente, a las autoridades del plantel y a todos los educandos la participación en cualquier actividad política opuesta al régimen, bajo la amenaza de severos castigos. Valiéndose de la delación fueron identificados estudiantes y maestros maderistas quienes empezaron a ser hostilizados y, aquellos que ocupaban cargos públicos, cesados sin miramientos.

El notorio fraude en la elección y el encarcelamiento de Madero, que dio el triunfo nuevamente a Díaz, abrieron paso a una resistencia pertinaz. La inconformidad y la protesta se expresaron en la manifestación del 7 de julio, organizada en la plazuela de San José, y las autoridades porfirianas respondieron de manera autoritaria. La manifestación fue disuelta violentamente por las fuerzas del orden: los representantes estudiantiles Alfonso G. Alarcón, Luis Sánchez Pontón — presidente y vicepresidente, respectivamente, de la mesa directiva de los estudiantes-, Gil Jiménez y Gregorio de Gante, entre otros más, fueron apresados. Se registraron desapariciones, expulsiones de las aulas y retiro de pensiones; ante estos hechos el rector del Colegio del Estado, José Rafael Isunza, renunció al cargo. 
A la reacción de la máxima autoridad del colegio se sumó la de los estudiantes quienes, de manera espontánea y emotiva, enarbolaron la solidaridad como estrategia en el corto plazo. Por principio de cuentas, desde el momento de su detención los líderes estudiantiles encarcelados tuvieron la solidaridad de todo el gremio estudiantil. Al ser conducidos a la primera audiencia para ver su causa, a pie, esposados y custodiados por una escolta, tratamiento con el que se pretendía exponerlos a la reprobación pública, en lugar de ello fueron arropados por la fraternidad estudiantil, que los acompañó proclamando su postura antireeleccionista a los cuatro vientos y coreando una consigna retadora: "¡Apenas hay dos en la cárcel, faltamos todavía muchos!", a la que añadieron una declaración de guerra que los acontecimientos del inminente noviembre de 1910 se encargarían de hacer realidad: "El gobierno nos ha declarado una hostilidad sin tregua, nosotros a la vez se la declaramos a él". Cuando se logró la libertad bajo caución de los detenidos, éstos nuevamente fueron recibidos afuera del Palacio de Justicia con un aplauso entusiasta. Además, quienes fueron privados de sus becas, entre los que podemos citar a David Vilchis, Tirso Sánchez Taboada y Alfonso Bonilla, dificultándoles la continuación de sus estudios, fueron amparados por sus compañeros: en consideración a la penuria económica con la que el gobierno castigaba a los estudiantes rebeldes se acordó distribuir entre los más necesitados su limitada reserva económica, que ascendía a 500 pesos y que había sido reunida para sufragar su participación en las inminentes fiestas del Centenario de la Independencia (Garmendia, 2008).

Pero, más allá de la respuesta espontánea y emotiva, los estudiantes también vislumbraron estrategias políticas en el mediano plazo. Tras el encarcelamiento y liberación de sus líderes, la primera medida fue rehacer su mesa directiva, relevando de la penosa tarea a Alfonso G. Alarcón y a Luis Sánchez Pontón y designando como presidente a Luis C. Quintana y como vicepresidente a Manuel Béistegui, medida que fue bien vista por las nuevas autoridades del Colegio del Estado quienes se solidarizaron con los acuerdos estudiantiles y con la política de sus antecesores.

Simultáneamente, gracias a los contactos establecidos con las mesas directivas estudiantiles de otros planteles educativos, se operó el público respaldo a los alumnos del Colegio del Estado. Los estudiantes de la capital de la república formularon una protesta por la persecución de la que eran víctimas sus compañeros poblanos:

La juventud estudiantil — decía el documento firmado por alumnos de las escuelas nacionales de Medicina, Ingeniería y Jurisprudencia - tiene derecho para creer que los estudiantes encarcelados en la ciudad de Zaragoza son víctimas de una injusticia. Enmudecer ante tamaña vejación sería faltar a los deberes del compañerismo y a la fraternidad que une a todos los estudiantes. Por eso, ante la indignación que enciende en nuestras almas todo lo que entraña un atropello, protestamos enérgicamente 
contra la prisión de los estudiantes don Alfonso G. Alarcón y don Luis Sánchez Pontón (Gámez, 1960).

El movimiento maderista primero y la posibilidad real de lograr el relevo en el poder político local y nacional, después, abrieron a los estudiantes un espacio de negociación. Paralelamente a las acciones de protesta contra el régimen porfirista la reflexión crítica sobre su entorno más próximo, el aula y la academia, devino en cauce natural a sus inquietudes. Es en este contexto en el que debemos valorar la participación de los estudiantes del Colegio del Estado en el Primer Congreso Nacional de Estudiantes.

\section{Celebración y reflexión: los estudiantes a escena}

Ese 1910, que se había previsto como el año de la celebración del primer centenario de la Independencia para que no sólo fuera inolvidable, sino para que el régimen porfiriano fuera identificado como el heredero directo de la tradición fundadora de la nación mexicana, los estudiantes del país aprovecharon los festejos para hacer patente su inconformidad ante las prácticas educativas prevalecientes al interior de sus instituciones y las pretensiones gubernamentales de centralizar la administración de los estudios superiores.

Desde los primeros días de febrero de 1910 los estudiantes metropolitanos de diversas instituciones empezaron a reunirse en la casa número 10 de la Primera Calle de la Perpetua, en la capital del país, con el objeto de acordar el modo más práctico de unir a todos los estudiantes de la república en un congreso nacional que tendría lugar como parte de los festejos del primer centenario de la Independencia.

Esta iniciativa ha sido abordada detenidamente por Velázquez Albo (2007) quien, después de examinar el contexto, rescata los documentos que nos ilustran, en primer lugar, sobre el nombre y el número de representantes, la cronología de las sesiones, los temas tratados, los discursos de inauguración, las ponencias, los argumentos principales y algunas evocaciones posteriores; y, en segundo lugar, sobre la recepción de la prensa al encuentro. Esta contribución es de obligada consulta para comprender las primeras etapas de la organización de los estudiantes mexicanos aunque, como señala Curiel Defossé (2008), se extraña un análisis más pormenorizado de lo que él llama las entretelas de la cuestión. Pero aun con esas observaciones de por medio y con el hecho de que su estudio se centra principalmente en los actores e instituciones educativas de la capital del país, no se puede negar que los primeros pasos en esa dirección están dados, lo cual permite abundar en el examen de la cuestión tomando, por ejemplo, la ruta de presentar casos particulares. 
La reunión en la que tomó forma la iniciativa de convocar al Primer Congreso Nacional de Estudiantes quedó documentada en el acta² que levantaron Enrique Ahumada, presidente de la Sociedad de Alumnos de Jurisprudencia; Gustavo P. Serrano, representante del presidente de la Sociedad de Alumnos de Ingeniería; Ernesto Fuente, presidente de la Sociedad de Alumnos de la Escuela Dental; Rafael Capetillo, representante del Instituto Científico de México; Amalio Ruiz, representante del presidente de la Sociedad "Ceres" de Agricultura; Atilano Guerra, presidente de la Sociedad de Alumnos de la Escuela de Medicina; Eduardo Ruiz, representante de la Escuela Superior de Comercio; y Alfonso Cabrera, autor del proyecto de la convocatoria, entre otros, el 10 de febrero de 1910.

En esa ocasión se leyeron, discutieron y reformaron las bases del proyecto de la convocatoria presentada por Alfonso Cabrera y, una vez aprobada con algunas correcciones, se procedió a designar al comité organizador del congreso. En ese punto surgió el primer problema, el de la representatividad; mientras Cabrera proponía que ese comité se formara con cinco integrantes, por consideraciones de orden práctico, otros argumentaban que ese era un número exiguo pues quedaba un gran número de escuelas de la capital sin presencia en dicho comité; en ese momento ni siquiera se planteó la posibilidad de que las instituciones educativas de provincia tuvieran algún tipo de representación en la organización de los trabajos. La cuestión se zanjó con la decisión de formar un comité de cinco integrantes al que se sumaría, como vocal, un representante de cada una de las escuelas que no formaran parte del propio comité. Y así, el comité quedó integrado por Atilano Guerra como presidente, quien superó en votos a Alfonso Cabrera; Santiago González de la Sociedad de Alumnos de Ingeniería como vicepresidente, Rafael Capetillo como tesorero, Enrique Ahumada como primer secretario; José Mares, presidente de la Sociedad "Ceres", como segundo secretario; y Ernesto Fuentes de la Escuela Dental y Eduardo Ruiz de la Escuela Superior de Comercio como vocales. En seguida se acordó fijar una cuota de cinco pesos por cada escuela, misma que se recabaría en la próxima sesión fijada para el 14 de febrero, para los primeros gastos del comité. La sesión concluyó con el encargo a todos los presentes de hacer extensiva la invitación al mayor número de escuelas posible.

Finalmente, la convocatoria ${ }^{3}$ fue lanzada el 20 de febrero de 1910 con las indicaciones siguientes: los gastos de organización del congreso correrían por cuenta de los estudiantes de la capital, la participación sólo sería posible por conducto de sus mesas directivas o representantes provisionales designados al efecto. A estas indicaciones se añadía la súplica, dirigida a los alumnos de todas las escuelas superiores, de que se organizaran con objeto de

\footnotetext{
${ }^{2}$ Archivo General de la Nación, Instrucción Pública y Bellas Artes (ACN, IPyBA), Actas y documentos del Primer Congreso Nacional de Estudiantes, 10 de febrero de 1910, vol. 318, exp. 41.

${ }^{3}$ AGN, IPyBA, Actas y documentos del Primer Congreso Nacional de Estudiantes, 20 de febrero de 1910, vol. 318, exp. 41 .
} 
examinar las bases propuestas para expresar su aceptación o para señalar las modificaciones y adiciones que consideraran necesarias a fin de redactar las bases definitivas del congreso, lo cual es un indicio del espíritu democrático que animaba la iniciativa estudiantil. Este señalamiento abrió la puerta a las opiniones de los estudiantes de provincia.

En la misma convocatoria se fijaron los asuntos a discutir: medios de comprobación del aprovechamiento escolar, recompensas y castigos, alumnos supernumerarios y libres u oyentes, integración del profesorado en las escuelas superiores, participación estudiantil en la factura de leyes y reglamentos, relación de las escuelas no oficiales con las oficiales, relaciones de las escuelas de la capital con las de los estados, perfeccionamiento moral y físico de los estudiantes, medios para fomentar la fraternidad y la solidaridad estudiantil. Se estableció también que cada escuela tendría un delegado, con excepción de las escuelas de la capital que tendrían tres, aunque estos tres representarían un voto, y que sus resoluciones se presentarían a las autoridades educativas, con la solicitud expresa al secretario de Instrucción Pública y a los gobernadores de los estados, para que sus opiniones se tomaran en cuenta al momento de formular las leyes de instrucción.

La recepción de la iniciativa entre los estudiantes de provincia empezó a manifestarse en el mes de abril; poco a poco se sucedieron tanto los oficios de declinación ${ }^{4}$ como los de aceptación a participar en el evento, comentarios y sugerencias para modificar las bases de la convocatoria de parte de las mesas directivas y sociedades de alumnos de diferentes puntos de la república.

Los estudiantes del Colegio del Estado de Puebla, reunidos el 18 de abril, acordaron proponer modificaciones a la redacción de la base novena; consideraron que debía precisarse el destino de las resoluciones del congreso para lograr, efectivamente, las reformas necesarias a las leyes de instrucción pública. También expresaron su preocupación de que, una vez concluido el congreso, la comisión ejecutora de las resoluciones solamente estuviera integrada por representantes metropolitanos, lo que les acarrearía una enorme carga de trabajo amén de que, con certeza, sólo podrían atender la problemática de las escuelas capitalinas, dejando sin atención a las de provincia. ${ }^{5}$

Paralelamente a la difusión y el desarrollo de los preparativos de esa primera reunión nacional del estudiantado se ponía en marcha la campaña política para la renovación del poder federal. El entusiasmo y la inquietud sacudieron el ánimo estudiantil porque era

\footnotetext{
${ }^{4}$ En el caso de Puebla, la Universidad Católica Angelopolitana y la Escuela de Artes y Oficios declinaron el honor de participar, no así el Instituto Metodista Mexicano, que acordó enviar tres delegados para representar a su Escuela Normal, a su Escuela de Comercio y a su Escuela Preparatoria, véanse los oficios respectivos en ACN, IPyBA, Cartas, oficios y telegramas dirigidos a Atilano Guerra, presidente del comité organizador del Primer Congreso Nacional de Estudiantes o al secretario del mismo, Enrique Ahumada, relativos a nombramientos de delegados al congreso, temas de exposición, ponentes e invitaciones diversas, 9 de julio, 29 de agosto y 17 de agosto de 1910, vol. 318, exp. 35.

${ }^{5}$ AGN, IPyBA, Cartas, oficios y telegramas dirigidos a (...), 18 de junio de 1910, vol. 318, exp. 35.
} 
imposible sustraerse a la conmoción del momento. El reclamo de "sufragio efectivo, no reelección" subió de tono en todo el país y la respuesta del gobierno porfirista a nivel nacional y local se distinguió por su autoritarismo, ya que persiguió y encarceló a los inconformes y consumó el fraude electoral. En este contexto la mención en la duodécima base de la convocatoria de que se invitaría al general Porfirio Díaz a presidir las sesiones de inauguración y clausura del congreso resultó más que controversial. Los estudiantes de algunos estados se rehusaron a participar argumentando que era indigno celebrar el nacimiento de un ideal que nunca se había respetado. Los estudiantes de Guadalajara y San Luis Potosí decidieron abstenerse antes que tolerar la presencia del dictador y mediante su ausencia expresaban su protesta; consideraban que el congreso era un ardid, un plan del gobierno para encausar al grupo estudiantil por un camino cuidadosa e inteligentemente preparado, para arrancarles su consentimiento a la ya odiosa centralización de la enseñanza y, de esa forma, justificar en lo posible el proceder del Ministerio de Instrucción Pública. Este fue el razonamiento de los estudiantes que se opusieron a la idea de concurrir al Primer Congreso Nacional de Estudiantes.

Los estudiantes del Colegio del Estado de Puebla y del Instituto Metodista Mexicano, por lo contrario, vislumbraron su participación en los trabajos del congreso como una oportunidad de negociación. Particularmente, la Junta Directiva de los estudiantes del Colegio del Estado de Puebla - a través de Luis G. Quintana, presidente y de Miguel Ibáñez, prosecretario- hizo contacto directo con el comité organizador para, entre otras cuestiones, informar del envío de varios telegramas a las sociedades de alumnos de San Luis Potosí y de Guadalajara exhortándolos a deponer su actitud e insistir en la conveniencia de su participación, aunque sus gestiones con los estudiantes de Guadalajara resultaron infructuosas, pues respondieron a sus excitativas declinándolas en todas sus partes. ${ }^{6}$

En su comunicado del 25 de agosto de 1910 presentaron al congreso a sus delegados, los cuales había sido electos el 13 de agosto: por la Escuela Preparatoria, Luis G. Quintana, propietario y Manuel Béiztegui, suplente; por la Escuela de Medicina, Alfonso G. Alarcón, propietario y Leopoldo González y Miguel Ibáñez, suplentes; por la Escuela de Ingeniería, Rafael Ibáñez, propietario y Serafín Monterde, suplente, además aprovecharon para enlistar todos los telegramas de exhorto que habían dirigido a los estudiantes de Guadalajara y San Luis Potosí, con lo cual dejaban constancia de su adhesión al proyecto.

El activismo de los estudiantes del Colegio del Estado de Puebla, que los acercó a las organizaciones metropolitanas, mereció la solidaridad de la comunidad estudiantil en los aciagos días de la represión que siguieron a la manifestación del 7 de julio en Puebla; les otorgó

\footnotetext{
${ }^{6}$ ACN, IPyBA, Cartas, oficios y telegramas dirigidos a (...), 23 de agosto de 1910, vol. 318, exp. 35

${ }^{7}$ AGN, IPyBA, Cartas, oficios y telegramas dirigidos a (...), 25 de agosto de 1910, vol. 318, exp. 35. De acuerdo con las ponencias que se conservan a estos delegados se unieron otros más.
} 
presencia en la inauguración del congreso con el discurso ${ }^{8}$ que, en representación de todos los estudiantes de provincia, pronunció Alfonso G. Alarcón, delegado de la Escuela de Medicina del Colegio del Estado de Puebla; y al término de los trabajos del congreso se expresó en el acuerdo de que el Segundo Congreso Nacional Estudiantil se celebraría en la ciudad de Puebla. ${ }^{9}$

Los grupos estudiantiles se reunieron durante el mes de septiembre de ese imprevisible 1910 y, durante dos semanas, los delegados se congregaron con el fin de estudiar y discutir ampliamente las propuestas para mejorar el estado de la instrucción pública y superior en México, y para formular conclusiones precisas que reflejaran las verdaderas necesidades y aspiraciones del grupo.

El delegado por la Escuela de Medicina del Colegio del Estado de Puebla, Joaquín Ibáñez Jr., presentó el texto intitulado Manera más conveniente de integrar el profesorado en las Escuelas Superiores, ${ }^{10}$ en el que reprobaba el procedimiento que se seguía en el nombramiento de profesores para dichas escuelas al señalar, en este delicado asunto, el Ejecutivo tenía las más amplias facultades para hacer tales nombramientos y que, por una dolorosa experiencia se había visto que, ministros y gobernadores, tan ignorantes como arbitrarios, por beneficiar al amigo, al favorito, al recomendado perjudicaban al grupo estudiantil. Así, para obtener una cátedra, resultaba más infalible una tarjeta de recomendación que el haber obtenido el mismo Premio Nobel. ${ }^{11}$ Ejemplificaba las terribles consecuencias de estas prácticas con lo que sucedía en el Colegio del Estado y, por eso, proponía que se favoreciera el examen de oposición como el medio más eficaz para el nombramiento de profesores. Previniendo lo que había atestiguado recientemente, también proponía que los profesores no pudieran ser removidos a menos que fueran sustituidos por quien ganara un examen de oposición, o mediante un juicio que se siguiera contra ellos ante las academias de profesores y sólo por causa de inmoralidad o ineptitud. Y cuando no fuera posible cubrir las cátedras vacantes a través de una oposición, las academias serían las que nombraran a quienes debían ocupar esos puestos, con lo que los alumnos tendrían derecho a poner a consideración de las academias, por escrito y con argumentos, a sus propios candidatos.

Sobre este mismo tema, Alfonso G. Alarcón presentó su Estudio acerca del nombramiento de los profesores en las escuelas secundarias ${ }^{12}$ en el que destacaba la importancia de la formación pedagógica en el cuerpo magisterial porque los programas más brillantes serían letra

\footnotetext{
${ }^{8}$ AGN, IPyBA, Alocuciones presentadas en la inauguración del Congreso por Salvador Jiménez Loza y Alfonso G Alarcón, en el salón de actos de la Escuela Metropolitana de Minería, septiembre de 1910, vol. 318, exp. 11.

${ }^{9}$ AGN, IPyBA, Acuerdos del Primer Congreso Nacional de Estudiantes... octubre de 1910, vol. 318, exp. 33.

${ }^{10}$ AGN, IPyBA, vol. 318, exp. 3, 44 fs.

${ }^{11}$ ACN, IPyBA, vol. 318, exp. 3, f. 12.

12 Alfonso G. Alarcón, Estudio acerca del nombramiento de los profesores en las escuelas secundarias, ponencia al Primer Congreso Nacional de Estudiantes, 1910. Véase AGN, IPyBA, vol. 318, exp. 17, 8 fs.
} 
muerta si fueran torpemente manejados, y la importancia de la participación del alumnado en el proceso de selección de profesores. Propuso el siguiente procedimiento: en sesión general de profesores y alumnos deberían discutirse la personalidad de los candidatos a ocupar una cátedra; en la discusión sólo podrían participar los profesores mientras que, los alumnos sólo tendrían derecho a escuchar sin opinar. Concluida la discusión se procedería a la votación en la cual sí podrían intervenir los alumnos.13 Su aspiración era que la opinión de los estudiantes sirviera para ilustrar el criterio del profesorado.

Rafael Ibáñez, delegado de la Escuela de Ingeniería de Puebla, disertó sobre Los principales defectos de los programas de instrucción secundaria. ${ }^{14}$ En la definición de dichos defectos concordaban, según él, alumnos y profesores, y a su juicio eran resultado de que los programas de enseñanza habían sido formados a semejanza de los que regían las escuelas europeas y de que, en su implantación, las academias de profesores sólo aplicaban mejoras en la forma, más no en el contenido. Así, lo que se invertía en la educación se desperdiciaba porque los malos profesores, ayudados de malos programas, echaban por tierra el propósito de producir hombres útiles y sabios profesionales. Entre los defectos más señalados apuntaba, en primer lugar, el carácter enciclopédico de los programas que imponían la memorización en detrimento del desarrollo de las facultades racionales como la inducción y la deducción; en segundo lugar, confundir la erudición con la ciencia, con lo que se valoraba al hombre dedicado a los estudios conforme a la cantidad y variedad de datos acumulados en su memoria, aunque fuera incapaz de relacionarlos; en tercer lugar, el desorden en los contenidos de los programas que, las más de las veces, eran copia de los índices de los libros utilizados; en cuarto lugar, la tendencia a centrar la educación en el desarrollo de aptitudes intelectuales, descuidando la preparación física y la disciplina; la ejercitación del cuerpo sólo se procuraba en los primeros años de manera irregular para luego ser abandonada. En resumidas cuentas, la instrucción secundaria se orientaba a la teorización y adolecía de la práctica, con lo cual se preparaba pobremente al alumnado para los estudios superiores en lo particular y para la vida en lo general.

Afirmaba que reformar convenientemente los programas era una empresa imposible para un individuo, no así para una comunidad como la que se había reunido en ese Primer Congreso Nacional y formuló las siguientes propuestas: los programas de instrucción secundaria debían, primero, modificar la extensión y la profundidad de los temas; segundo, favorecer la enseñanza práctica por encima de los estudios teóricos; tercero, suprimir las asignaturas inútiles sustituyéndolas por el estudio de temas útiles en la vida práctica; cuarto, suprimir los exámenes de gimnasia y exigir la asistencia al gimnasio de la escuela durante todo el tiempo que durara

\footnotetext{
${ }^{13}$ AGN, IPyBA, vol. 318, exp. 17, f. 7.

${ }^{14}$ AGN, IPyBA, vol. 318 , exp. 13, 38 fs.
} 
la instrucción; y, finalmente, reclamaba el derecho de los estudiantes a promover la corrección de los programas de enseñanza. ${ }^{15}$

Por su parte, el delegado por la Escuela Preparatoria y estudiante de Jurisprudencia, Luis G. Quintana, discurrió sobre las Escuelas preparatorias, profesionales, \&... de los estados. Su conveniencia y sus relaciones con las escuelas de la capital, ${ }^{16}$ y en su extensa ponencia abordó el papel del Estado en la organización de la enseñanza, así como los límites que debía tener el poder estatal para legislar en materia educativa con el fin de argumentar su enérgico rechazo a las intenciones gubernamentales de centralizar la administración de la enseñanza, cuestión de suma trascendencia para las escuelas y los estudiantes provincianos. Trató, primeramente, la cuestión desde el punto de vista jurídico interpretando los textos constitucionales y el aspecto filosófico legal, pasando revista a los numerosos inconvenientes que acarrearía la centralización de los estudios. A su juicio, ésta produciría la uniformidad monótona en leyes y programas y le quitaría toda iniciativa a los estados degenerando en abuso, y el principio de orden invocado por los partidarios de la centralización se convertiría en instrumento de tiranía o en máxima de monopolio. ${ }^{17}$ Repasó, sucintamente, la historia de las universidades europeas y americanas para destacar su espíritu y comparar su trayectoria con la de las instituciones nacionales, en general, y con la de las instituciones educativas poblanas, en lo particular; de ahí derivó la urgente necesidad de promover la fraternidad y la solidaridad estudiantiles, exponiendo la influencia que éstas habían tenido en todos los tiempos y en todos los acontecimientos políticos y sociales de las naciones europeas.

Ante el decreto del 26 de mayo de 1910 que el Congreso de la Unión expidió para la fundar la universidad nacional, no quedaba más que reclamar la conservación, en los estados, de las escuelas profesionales independientes y la unificación en los programas de enseñanza para que, de esta manera, los alumnos de un estado pudieran revalidar sus estudios, ya en las escuelas metropolitanas, ya en las de otros estados y de esta manera no entorpecer la conclusión de sus estudios. ${ }^{18}$

Los delegados del Colegio del Estado de Puebla procuraron tomar parte activa en las discusiones, actuaron de manera concertada para que su opinión tuviera mayor fuerza y lograron que la asamblea estudiantil tomara en consideración algunas de sus propuestas. En las resoluciones de ese Primer Congreso Nacional de Estudiantes se acordó que el método combinado de exámenes y reconocimientos era la mejor manera de comprobar el aprovechamiento de los alumnos en las escuelas superiores. Se recomendó reformar el método para asignar premios y castigos: los premios los debía asignar un jurado formado por un grupo

\footnotetext{
${ }^{15}$ AGN, IPYBA, vol. 318, exp. 13, fs. 37-38.

${ }^{16}$ AGN, IPyBA, vol. 318, exp. 22, 52 fs.

${ }^{17}$ AGN, IPyBA, vol. 318, exp. 22, f. 20.

${ }^{18}$ AGN, IPyBA, vol. 318, exp. 22, f. 51.
} 
de,alumnos avanzados, presidido por el director de la escuela, y el sistema de castigos, tal y como existía, debía desaparecer; los alumnos supernumerarios, libres u oyentes debían recibir la misma educación sin ninguna clase de distinción, con todos los derechos y todas las obligaciones para evitar la charlatanería; el profesorado tendría que ser seleccionado por el método de oposición y solamente a petición del alumnado se admitirían profesores por elección, quienes no podrían permanecer más de 10 años en la posesión de la cátedra; se consideró de urgente necesidad la creación de escuelas normales superiores; se estableció que los alumnos tomaran parte en la formación de las leyes y reglamentos de las escuelas; se dispuso que los estudios de las escuelas no oficiales y privadas merecieran reconocimiento, siempre que sus programas estuvieran aprobados de antemano; se recomendó la creación de escuelas preparatorias, de agricultura, de artes y oficios, rurales y especiales y normales en todo el país, con programas de estudios uniformes que permitieran la equivalencia de estudios y la revalidación para no obstaculizar el progreso de los estudios; se acordó el perfeccionamiento físico y moral de los estudiantes de las escuelas superiores, la práctica obligatoria de la gimnasia y la participación en sociedades de alumnos para alentar y normar las buenas costumbres además de estimular sus facultades intelectuales; y, como medio más eficaz para fomentar la fraternidad estudiantil, se proclamó la Federación Mexicana de Estudiantes, conforme a las bases que la comisión ejecutiva presentaría posteriormente a las escuelas representadas en el Primer Congreso Nacional de Estudiantes y que, desde esa fecha, serían consideradas federadas por el voto unánime de la asamblea. ${ }^{19}$

En suma, las resoluciones de ese Primer Congreso Nacional de Estudiantes se orientaron a transformar las normas y las prácticas que regían la vida escolar en los establecimientos de enseñanza superior, exhibiendo problemáticas y preocupaciones que afectaban de manera común tanto a los estudiantes metropolitanos como a los de provincia. Y, con este objetivo, analizaron y cuestionaron las políticas gubernamentales en materia educativa.

Paralelamente, la celebración de este Primer Congreso Nacional de Estudiantes dio cauce al activismo de una nueva generación de letrados que, posteriormente, se distinguirían en el ámbito de la cultura y en el ejercicio de responsabilidades públicas. En el caso de los estudiantes del Colegio del Estado de Puebla podemos señalar a Luis G. Quintana, abogado, quien sería rector de la Universidad de Puebla en 1924; Luis Sánchez Pontón, abogado, quien sería secretario de Educación en la administración del general Ávila Camacho; Alfonso G. Alarcón, médico, que llegaría a ser diputado en la legislatura maderista y quien se distinguió como escritor y científico haciendo notables aportes a la medicina pediátrica; sirvió en el Departamento de Salubridad Pública en la Ciudad de México y ocupó, de 1938 a 1941, la rectoría de la Universidad de Puebla; Alfonso Cabrera, médico, también se desempeñó como

${ }^{19}$ Resoluciones del Primer Congreso Nacional de Estudiantes, octubre de 1910, AGN, IPyBA, vol. 318, exp. 32, 3 fs. 
diputado en la legislatura maderista y, al triunfo del constitucionalismo, fue electo gobernador del estado de Puebla.

Y, de esta manera, desde las aulas, se ensayó la configuración de un nuevo tipo de actor social, capaz de constituir nuevas formas de organización y representación colectiva.

\section{Observaciones finales}

Las instituciones educativas pueden ser visualizadas como los espacios de intersección entre las vidas singulares de los hombres y los contextos sociohistóricos que permitieron su fundación y funcionamiento. En la máxima casa de estudios de Puebla, de larga y azarosa existencia, se expresaron los cambios y las permanencias de su entorno social.

La secularización de la enseñanza, las penurias económicas y la inestabilidad política de un Estado en formación, las tensiones entre la Iglesia y el Estado por el control de la educación, lo mismo que los intentos por modernizar la enseñanza conmovieron la marcha del centro de enseñanza superior más prominente del estado de Puebla sin perder la función social para la que fue concebido desde su origen: formar a la élite letrada, capaz de dirigir la vida cultural y la administración de la sociedad.

Los cambios operados en el siglo XIX, orientados a propagar la educación a capas más amplias de la población, tuvieron como consecuencia la modificación del perfil de los actores del proceso educativo en El Colegio del Estado. El acceso a la enseñanza superior se abrió a estudiantes de diversa condición social, provenientes de todos y cada uno de los distritos del estado, seleccionados por su buen desempeño escolar por las comisiones de educación distritales. El contacto directo con el proceso de generación de conocimientos y el hecho de estar en un proceso de formación profesional, mediante el cual se aspiraba a modificar el estatus social y una ventajosa inserción en el mercado laboral, configuraron uno de los sectores modernos de la sociedad: los estudiantes. Su identidad como grupo se fue construyendo con la convivencia en el aula y en los recintos escolares donde compartían tanto los desaciertos de la práctica educativa como la precariedad de la vida estudiantil, pues una gran mayoría dependía de becas y subvenciones gubernamentales. La preocupación por su futuro laboral y el reconocimiento de sus responsabilidades sociales los orientó al reclamo de dos tipos de reivindicaciones: unas de carácter gremial relativas a su condición de estudiantes, tales como el perfeccionamiento de los sistemas de enseñanza y la gratuidad de la educación; y otras, de índole política, como son la participación en la reglamentación de sus instituciones, el cuestionamiento a las políticas gubernamentales en materia educativa y, de manera más general, el derecho a participar en la conducción general de la sociedad. 
De manera general, desde finales del siglo XIX, los estudiantes de enseñanza superior y sus manifestaciones de descontento aparecieron en la escena política. Progresivamente, sus reclamos salieron del claustro universitario y se inclinaron hacia la crítica a las decisiones gubernamentales. Las sociedades de alumnos de los planteles de enseñanza superior empezaron a avizorar la urgencia de constituir instancias representativas de sus intereses y el primer gran esfuerzo, en este sentido, fue la organización del Primer Congreso Nacional de Estudiantes, celebrado en 1910, en donde asumieron una postura reflexiva y crítica al régimen.

Los estudiantes poblanos, que llevaron la representación de la comunidad estudiantil del Colegio del Estado de Puebla a ese congreso, centraron sus intervenciones en la crítica a la integración y formación del profesorado tanto de instrucción secundaria como de enseñanza superior, a los programas de estudio, a los métodos de enseñanza y a la pretensión gubernamental de centralizar la administración de la educación. Con ello evidenciaron su comprensión de los límites de la práctica educativa en su propia institución y los riesgos que implicaban las políticas federales en materia educativa. Inconformes con el rumbo que seguía la dictadura porfirista optaron por la organización, aspirando a convertirse en interlocutores de un régimen que no aceptaba el diálogo. Aun así, sus iniciativas en favor de la organización estudiantil y sus propuestas para reformar la práctica educativa en los estudios superiores trascendieron la coyuntura revolucionaria y, paulatinamente, pasarían a formar parte de la vida escolar tanto local como nacional.

\section{Referencias}

Archivos

AGN Archivo General de la Nación.

Fondo Instrucción Pública y Bellas Artes (IPyBA), Primer Congreso Nacional de Estudiantes, 1910.

BHJML Biblioteca Histórica José María Lafragua, Fondo Colegio del Estado, Puebla.

Bibliografía

Alarcón, Alfonso G. (1910), "Estudio acerca del nombramiento de los profesores en las escuelas secundarias", ponencia al Primer Congreso Nacional de Estudiantes, septiembre de 1910, México.

Carmagnani, Marcelo (2004), El otro occidente. América Latina desde la invasión europea hasta la globalización, Fondo de Cultura Económica, México.

Casián, Francisco L. (1998), "Una remembranza del Colegio del Estado", en Alberto Pérez Peña, El Colegio del Estado de Puebla en el primer centenario de su vida civil. 1925, edición facsimilar, Vicerrectoria de Investigación y Estudios de Posgrado/Dirección de Fomento Editorial/BUAP, México, pp. 109-116.

Curiel Defossé, Fernando (2008), "La participación estudiantil en el Congreso de 1910. Documentos históricos", Perfiles educativos, vol. 30, núm. 122, pp. 141-143.

Fuentes Bazán, María Eugenia (1999), "Los estudiantes del Instituto Metodista Mexicano y la Revolución mexicana", Dimensión Antropológica, vol. 17, septiembre-diciembre, pp. 123-146. 
Gámez, Atenedoro (1960), Monografía histórica sobre la génesis de la revolución en el estado de Puebla, Instituto Nacional de Estudios Históricos de la Revolución Mexicana, México.

Garmendia, Arturo (2008), "Fraude electoral y los estudiantes del Colegio del Estado en 1910", Tiempo Universitario, año XI, núm. 10, agosto, [documento html disponible en: http://www.archivohistorico. buap.mx/tiempo/2008/allg10.htm> (consultada en 11 de novembre de 2017)].

Gobierno del Estado de Puebla (CEP)(1901), Memoria instructiva y documentada que el Jefe del Departamento Ejecutivo del Estado presenta al XVI Congreso Constitucional, Imprenta de la Escuela de Artes y Oficios del Estado, Puebla.

(1903), Memoria instructiva y documentada que el Jefe del Departamento Ejecutivo del Estado presenta al XVII Congreso Constitucional, Imprenta de la Escuela de Artes y Oficios del Estado, Puebla.

(1905), Memoria instructiva y documentada que el Jefe del Departamento Ejecutivo del Estado presenta al XVIII Congreso Constitucional, Imprenta de la Escuela de Artes y Oficios del Estado, Puebla.

(1907), Memoria instructiva y documentada que el Jefe del Departamento Ejecutivo del Estado presenta al XIX Congreso Constitucional, Imprenta de la Escuela de Artes y Oficios del Estado, Puebla.

(1911), Memoria instructiva y documentada que el Jefe del Departamento Ejecutivo del Estado presenta al XXI Congreso Constitucional, Imprenta de la Escuela de Artes y Oficios del Estado, Puebla.

Guerra, François-Xavier (2003), México: del antiguo régimen a la revolución, $2^{\mathrm{a}}$. ed., Fondo de Cultura Económica, México.

Ibáñez, Joaquín (1910), "Manera más conveniente de integrar el profesorado en las Escuelas Superiores", ponencia al Primer Congreso Nacional de Estudiantes, septiembre de 1910, México.

Ibáñez, Rafael (1910), "Principales defectos de los programas de instrucción secundaria", ponencia al Primer Congreso Nacional de Estudiantes, septiembre de 1910, México.

Lomelí Vanegas, Leonardo (2001), Breve historia de Puebla, El Colegio de México y Fondo de Cultura Económica, México.

Quintana, Luis G. (1910), "Escuelas preparatorias, profesionales, \&... de los estados. Su conveniencia y sus relaciones con las escuelas de la capital"ponencia al Primer Congreso Nacional de Estudiantes, septiembre de 1910, México.

Ríos Zuñiga, Rosalina (1998), "Educación y autonomía regional: origen de los institutos literarios (18231832)", en Leticia Pérez Puente (coord.), De maestros y discípulos: México, siglos XVI-XIX. Universidad Nacional Autónoma de México-Centro de Estudios sobre la Universidad, México.

Secretaría de Economía (SE) (1956), Estadísticas sociales del porfiriato, 1877-1910, Secretaría de Economía/ Dirección General de Estadística-Talleres Gráficos de la Nación, México.

Tecuanhuey Sandoval, Alicia (1994), Cronología políica del Estado de Puebla, Fomento Editorial BUAP, México.

Velázquez Albo, María de Lourdes (2007), La participación estudiantil en el Congreso de 1910. Documentos históricos, UNAM-IISUE, México.

María de Lourdes Herrera Feria. Profesora-investigadora en el Colegio de Historia de la Benemérita Universidad Autónoma de Puebla. Doctora en Historia por la Freie Universität Berlin. Sus líneas de investigación son la historia social de la educación, y secularización y modernización en Puebla. Pertenece al Sistema Nacional de Investigadores (nivel I). Becaria en 2007 y 2012 del Servicio Alemán de Intercambio Académico; obtuvo la Cátedra América 
Latina 2016-2017 en la Universidad de Toulouse Jean Jaurès (Institut Pluridisciplinaire pour les Études sur les Amériques). Publicaciones recientes: "Solicitud del obispo Victoriano López Gonzalo para fundar un Hospicio en el Colegio de San Ildefonso de Puebla", Estudios de Historia Novohispana, núm. 54, 2016, pp. 92-102; "La circulación de las ideas asistencialistas y su impacto en las obras de la Beneficencia Pública de Puebla", en J. M. Cerdá et al. (edits), El auxilio en las ciudades. Instituciones, actores y modelos de protección social. Argentina y México, siglos XIX y XX. El Colegio Mexiquense A. C. y Centro de Estudios Históricos Prof. Carlos S. A. Segreti, Zinacantepec, 2015, pp. 53-82; y "La fundación del Hospicio de Pobres en Puebla de los Ángeles, 1771-1832", Revista Mexicana de Historia de la Educación, vol. III, núm. 5, 2015, pp. 69-96. 